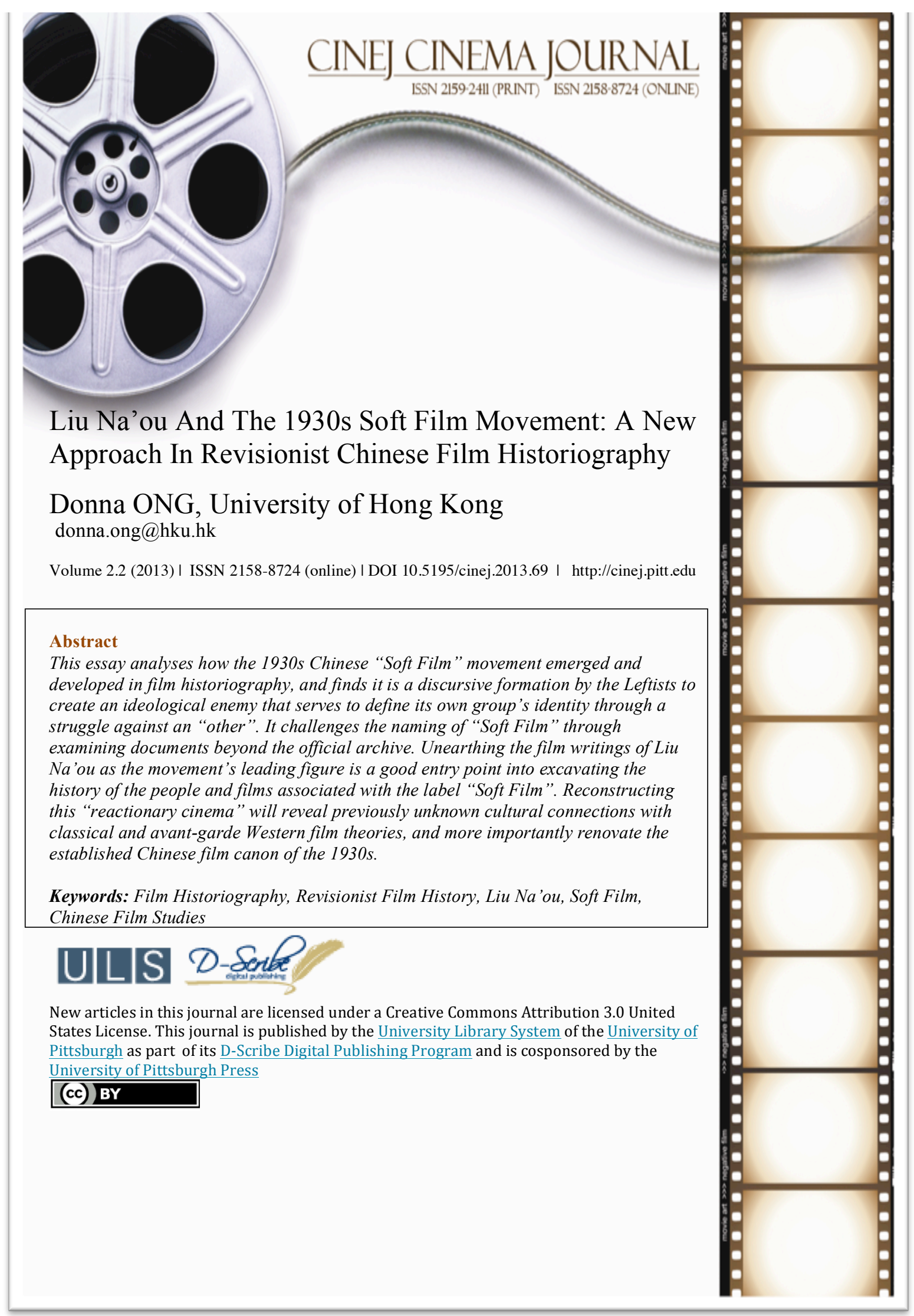




\section{Liu Na'ou and the 1930s Soft Film Movement: A new approach in revisionist Chinese film historiography}

\section{Struggles in Chinese Film historiography}

Since the 1950s, scholars of early Chinese film history have lamented the difficulty in writing an accurate and comprehensive account of the pre-1949 Chinese film industry. This is attributed to the limited access to existing material and the absence of a systematic record. ${ }^{\mathrm{i}}$ The 1963 Maoist account in The History of the Development of Chinese Cinema by Cheng Jihua et al. was the first comprehensive study on Chinese film history and has since become the authoritative text for Republican era Chinese film. ${ }^{\text {ii }}$ Immediately following the era of reform and opening up in the 1980s, there was a revival in the Leftist film history that further entrenched the book's historical account in the official discourse. It was only during the mid to late 1990s that there have been serious efforts to revise and challenge this politicized historiography. Despite the major headway made by scholars, one key issue that has yet to be fully explicated is the Leftist or Left Wing writers discursive construction of the main film ideological enemy in the 1930s, the so-called "Soft Film" movement.

According to the official discourse, the Leftist ideological construction of the "Soft Film", as part of the "Hard Film vs. Soft Film debate" between 1931-1935, was a crucial event in the rise and development of the Left Wing film movement. With the background of growing Japanese aggression with the "918" and " 128 " incidents in Northeastern China, ${ }^{\text {iil }}$ the Leftists' rise was a response to a nationalist call to bring patriotism and social justice to the screen. Meanwhile, what were taken as "Soft" films played the role as a theoretical proponent of the ruling Kuomintang's violent suppression of the Leftists, and worse, a traitorous collaborator of the Japanese occupied government during the war years. The "hanjian" or traitor stigma attributed to Liu Na'ou and Mu Shiying, and the subsequent infamous assassination of these important figures of the "Soft Film" afflicted the reputation of term so heavily that many scholars more than seventy years on are still unable to overlook their treacherous crimes.

The initial appearance of "Soft Film" and "Hard film" carried no negative connotations. They were first coined by the film critic Huang Jiamo in his "Hard film and Soft Film" article published in the Modern Screen journal on December 1, 1933. Huang voiced his opposition to the wave of overly politicized Leftist films appearing on screen and claimed that films should be made to entertain and not indoctrinate the masses. Speaking against the Leftist's critical realism and the "Hard Films" that were political propaganda to him, Huang advocated the development of "Soft Film" which he defined as "ice-cream for the eyes and a sofa for the soul" - the most famous quote that has come to define the term. The 
controversial article sparked a bitter row between critics that advocated "film for art and entertainment", and the Leftist camp dedicated to using film to transform society and serve the besieged nation. The association of leading "Soft Film" critics with Japanese imperialists during the war, however, only served to cement the Leftist conviction that "Soft Film" ideas were reactionary and traitorous.

The association of "Soft Film" with betraying nationalist interests has since put the "Soft Film" in an awkward position in Chinese film historiography. For sure, the history of Republican era film remains highly problematic for its over-dependence on the Maoist account in The History of the Development of Chinese Cinema, as it is a fact acknowledged by Chinese film history scholars. Efforts since the 1990s have been made by scholars from the PRC, Taiwan and overseas to re-evaluate the "Soft Film" movement including its leading figure Liu Na'ou. However, even though Liu $\mathrm{Na}$ ' ou and his ideas of film as art have been given more recognition as scholars begin to dig deeper into the writings from the "Soft Film" defenders, none have managed to make a complete breakthrough in revealing its complexity and core components beyond the surface. Zhang Zhen notes in her study, An Amorous History of the Silver Screen that "critics remain reluctant to re-evaluate the Soft cinema, because it would entail the rewriting of Chinese film history as a whole". "She also notes that this contrasts the way that Neo-sensationalist literature, which also involved Liu $\mathrm{Na}$ 'ou and $\mathrm{Mu}$ Shiying, has received its due place in literary history since the 1980 s. One can infer that the politicized nature and the nationalist judgments regarding the "Soft Film" explains why many scholars are not only unwilling, but also afraid to dig too deep. The Leftist film history has larger implications that transcend the world of film to constitute the formative years of the Chinese Communist Party (CCP) and overall communist revolution in China.

A highly restrained and perhaps self-censoring revisionist effort means contradictions and ambiguities when it comes to the identity and nature of "Soft Film". The biggest conundrum that is most apparent in writings on the 1930 s is the struggle over the light notion of "Soft Film" as one linked to "film as entertainment" in Huang Jiamo's writing, or "film as art" as elaborated in the writings of Liu Na'ou. One closer look into the debates immediately reveals a significant inconsistency, that is, although Liu Na'ou was given the most attention in critical views on "Soft Film", he never used or associated his writings with the term. Some PRC scholars holding a revisionist historical view have appropriately pointed out that Liu's sophisticated ideas on film as art far exceed Huang Jiamo's original "ice-cream for the eyes" definition. This poses a challenge to the very notion of "Soft Film" as a movement with only one key component. It must be said that any continued referral to Liu's ideas as associated with or representative of "Soft Film" is proven by the record as problematic. Furthermore, basic information such as the dates of birth and death of Liu Na'ou remained debatable until his 
biography was published in 2001, thus adding to the ambiguities linked to "Soft Film" that has the status of an enigma rather than a self-explanatory movement. To clear the grounds of this debate in Chinese film history is thus necessary.

This essay analyses the emergence of the "Soft Film" in Chinese film historiography and borrows from Foucault's Archeology of Knowledge to argue that it was in fact a discursive formation by the Leftists to construct an exemplar of reactionary cinema. $v$ The Leftist struggle to promote "critical realism" in film against imperialist and bourgeois proponents represented by the "Soft Film" camp, is hence crucial in constructing its own history and identity as a revolutionary force. As the "Soft Film" has been mentioned in almost all studies following the publication of History of the Development of Chinese Cinema, I will show the lasting legacy the book has left on Chinese film historiography both inside and outside the Mainland, and identify what rules continue to govern the field with regard to the "Soft Film".

I conclude by suggesting that the way to completely revise the history of the socalled "Soft Film", is by going beyond the established archive, and studying the complete works of the identified "Soft Film" critics and their affiliates. The growing scholarly attention on the leading critic Liu Na'ou's film writings has already opened up an exciting new perspective into the 1930 s film. It both challenges the simplistic reading of the term "Soft Film" as "ice-cream for the eyes" and an artistic front for feudalistic and imperialist forces. His citations and translations of Western mainstream to avant-garde films and theories, reveal a distinct intellectual and cultural connection between 1930s European and Chinese film that has yet to be explored. Extending close readings into other affiliated critics, their films and backgrounds will reveal the missing pieces to construct a new and comprehensive picture of all that has been obscured by the term "Soft Film".

\section{II. "Soft Film" as a discursive formation}

The "Soft Film" appears in historical studies of the period for the first time in History of the Development of Chinese Cinema in 1963. Prior studies which had mostly focused on industry development and milestone films made no mention of either the Leftists and "Soft Film" camps, nor the theoretical debates that took place between them. ${ }^{\text {vi }}$ As the book was written under an intense political environment when Party politics dominated all aspects of life, this book places primary emphasis on the Leftist's role in bringing about the wave of socially conscious and patriotic films.

CINEJ Cinema Journal: Donna ONG 
Interestingly, it is in this political context that the "Soft Film" too is mentioned for the first time and is weaved into the narrative of the Leftist rise and development in the film industry. The amount of attention given to elaborating the "Soft Film" is indicative of its importance in the Leftist's account of this period. In particular, the debate is treated as a crucial moment in the Leftist led "New Film Culture Movement's" struggle against "evil" forces, and ideological exchanges with "Soft Film" critics enabled the Leftist film writers and critics to improve their understanding of film and strengthen their position in film production. ${ }^{\text {vii }}$

In the official history, Cheng delineates the articles and critics of the debate that lasted from 1933-1935. He extends the 1930s Leftist's moralist criticism of the "Soft Film's" failures and evils as reactionary, feudalistic and imperialist. His take on the "Soft Film" aesthetic argument expounds the 1930s Leftist critics belief that it was merely a disguise for their reactionary goals. Moreover, the "Soft Film's" argument for film form over content, and emphasis on art and entertainment over politics is anti-revolutionary for disregarding social responsibilities to reflect social realism and injustices.

From this politicized reading, Cheng accuses the "Soft Film" of being part of the Kuomintang's "encirclement" to exterminate the Leftists and control their growing presence and influence in the film industry. While the Leftists were suffering from violent attacks and arrests from Kuomintang black shirts and police, theoretically the "Soft Film" sought to undercut their work and position in the film industry. Since the publication of Huang Jiamo's article Hard Film and Soft Film that instigated the debate came just twenty days after the violent attack on Yihua studio to crackdown against Leftist filmmakers on November 12, 1933, the timing suggests the two events were directly linked and connected to the Kuomintang's "white terror" campaign.

Cheng extends this ideological battle into the field of film production. He claims that due to the defeat of the "Soft Film" in the theoretical debate, the advocates began to enter the film industry under the protection and support of the Kuomintang. Cheng uses Yongyuan de weixiao (Eternal Smile) (Wu Cun; screenplay by Liu Na'ou, 1937) to illustrate how "Soft Film" promoted Kuomintang ideology that people should sacrifice themselves to uphold the law, which he interprets to mean support for the Nationalist government's classist power structure that justifies executions of revolutionaries. Cheng accuses the "Soft Film" theorists of being hypocritical for criticizing Leftists of using film to advocate ideology, but doing exactly that in Yongyuan de weixiao. He also notes that the major "Soft Films" were made at Yihua studio starting from 1935 with the film Huazhu zhiye (Wedding Night, Yue Feng, 1936) up until 1937 when the antiJapanese war broke out. A total of nineteen films made within one and a half years are said to fall into three categories: comedy (e.g. Huasheng 
Guniang Tomboy/ Miss Changebody, Fang Peilin, 1936), romance (e.g. Chulian First Love, Liu Na'ou, 1937) and detective films (e.g. Xinhun daxuean Murder at the Wedding, Wang Cilong, 1936). He also says that for a brief stint under the auspices of Zhang Shichuan, Mingxing studio also produced several "Soft Films".

Hayden White's idea that every history is shaped by its "metahistory" or the archetypal historical narrative that the historian uses to shape and structure a story about the past, provides a good framework to deconstruct and analyze this classic text on Chinese film history. The way historical events are selected and interpreted into a story in History of the Development of Chinese Cinema fits well into White's category of "romantic" emplotment. This is described as "a drama of self identification symbolized by the hero's transcendence of the world of experience, his victory over it and his final liberation from it... It is a drama of the triumph of good over evil, of virtue over vice, of light over darkness and the ultimate transcendence of man over the World in which he was impressed by the fall" viii This historical narrative is hence an obvious case of a history written by the winners and classic example of a grand historical narrative that is guided by a certain ideology. The corresponding formist argument that "aims at the identification of the unique characteristics of objects inhabiting the historical field"ix is also characteristic of this type of narrative, whereby unique acts by unique individuals or entities bring about historical change. As White identifies, it runs the danger of "generalization about processes discerned" and is "inclined to lack conceptual precision"x. This aptly describes the established criticisms of the text's ideological biases and the pressing need to rewrite Republican era Chinese film history.

Despite the obvious biases against the "Soft Film", the amount of attention and importance given to it in the book has inadvertently helped to reserve it a place in mainstream film historiography. It is clear that after Cheng Jihua's book, almost all historical studies mention Liu Na'ou and the "Soft Film", albeit with inaccuracies, and marks the "Hard film vs. Soft Film" debate as a major event in Chinese film history. Going one step further in challenging this Grand Narrative history, it appears that the "Soft Film" is in fact what Foucault calls a "discursive formation" by the Leftists. ${ }^{\mathrm{xi}}$

In defining its own identity as the saviors of the nation and defenders of justice, the "Soft Film" serves as the projected other in playing the role as reactionary cinema. The terms in which scholars and historians study and discuss Republican era film and specifically the 1930s are hence part of larger discursive regimes or systems of power and regulation set in the History of the Development of the Chinese Cinema.

CINEJ Cinema Journal: Donna ONG 
The intense political conditions in which this book was written during the antirightist movement in China are especially telling of the forces that influenced the way in which the history of cinema has been written and understood. Despite its devout Marxist stance, the book was still banned during the Cultural Revolution and the principal author Cheng Jihua imprisoned for eight years. The 1930s Leftist films he praised as forerunners of Socialist art were accused of being insufficiently proletarian - although many believe that the real reason was it brought up Chairman Mao's wife and Gang of Four member Jiang Qing's unillustrious career as a second rate actress in 1930s Shanghai cinema under the stage name Lan Ping.

As the only comprehensive and systematic account of the 1930s history, its basis for all succeeding studies and accounts shows the authority it has on setting the objects and rules of the historical discourse. Subsequently, the "Soft Film" discourse has become so engrained in the field of Chinese film history that it has now been taken for granted. It is hence clear why scholars since the publication of History of the Development of Chinese Cinema have challenged, developed and complicated the "Soft Film" which remains ambiguous and enigmatic today. Deconstructing and analyzing the way in which the "Soft Film" has been discussed and dealt with in historical studies of Chinese films, reveals that as a discursive formation it is not in fact a cohesive movement as previously understood.

\section{Lasting legacy of History of the Development of Chinese Cinema on film historiography}

Within a decade of Cheng Jihua's monumental book, two direct challenges were made by a Taiwanese film historian Du Yunzhi in Zhongguo Dianying shi (Chinese Film History) ${ }^{x i i}$ and American scholar Jay Leyda in Dianying: An account of Films and the Film Audience in China ${ }^{x i i i}$ (the first English language full length historiographical account of Chinese film) - both published in 1972 and both provide an alternative definition to the "Soft Film" or allusions to it.

Du Yunzhi's comprehensive study of Chinese film history published in Taiwan responds to Cheng's history by providing a contradictory Kuomintang account of the Leftist rise in the 1930s as detrimental to the film industry's development. It is careful not to use the term "Soft Film" for the critics that engaged in the debate with the Leftists. While Leyda does use of the term "Soft Film", he only uses it in reference to production and does not mention the theoretical debates that play a major role in Cheng's account. Leyda instead uses the term "Soft Film" to refer to "low films" made at Yihua studio and by right wing personnel at Mingxing studio, citing the examples of Three sisters, The Heart of a Beauty, Madame Mo, Enemy of Women, Orchid in the Ravine.

CINEJ Cinema Journal: - Liu Na'ou and the 1930s Soft Film Movement

72

Volume 2.2 (2013) | ISSN 2158-8724 (online) | DOI 10.5195/cinej.2013.69 | http://cinej.pitt.edu 
Interestingly, Du and Leyda's equally comprehensive and lengthy studies have failed to alter the terms for discussions about the "Hard film vs. Soft Film" debate in future film historiography. The lasting legacy of History of the Development of Chinese Cinema on the study of Chinese film historiography may be credited to the Leftist film history's revival with the start of the era of reform and opening up in China. As the book was condemned and banned during the Cultural Revolution, the book was only officially launched nearly twenty years later in 1981. It was closely followed by a conference the following year in 1982 with surviving veterans of the Left wing film movement such as Xia Yan and Ke Ling. The series of public activities and publications which also re-released 1930s film classics was important in reviving the Leftist's role in Republican era film history. Moreover, it further elaborated the role of the Left wing film movement in bringing the May Fourth movement into the film industry and their heroism in bringing patriotism to film at a time of national crisis. ${ }^{\text {xiv }}$

This has led to the deep entrenchment of the Leftist myth or glorification, and reconstruction of the Left Wing film movement. By extension, this also highlighted the Communist Party's role as its successor in influencing the 1930s film industry. The publication of the books Chinese Leftist film movement (Chen Bo, 1993) and Selections of Chinese film criticism in the 1930s (Zhongguo dianying yishu yanjiu zhongxin, 1993) are examples of post-80s publications devoted to establishing the Leftist film canon and celebrating the Leftist film movement as a cohesive and powerful force in the 1930s. It is worthy to note the inclusion of the debate with the "Soft Film" in both of these anthologies.

This Leftist revival in the film industry during the 1980 s, contrasts the modernist revivals in the literary and cultural studies of the same period both in the Mainland and abroad. The early period of reform and opening up fostered the belief that the revolution was over and there was a need to abandon political ideology. International and consumerist culture in the 1980s seemed to have inspired scholars to look to 1930 s Shanghai as a model. Perhaps due to the politically sensitive nature of film history, it was only in the 1990s that the major breakthroughs in modern literary studies began to move into the field of film studies to spark a second wave of revisionist history that questioned the problematic political biases in film history. The Chinese translation of Film History: Theory and Practice (1985) by Allan and Gomery is also said to have been particularly influential in changing the attitudes of film scholars in the Mainland. ${ }^{\mathrm{xv}}$

The increasing awareness to reevaluate the orthodox Marxist narrative saw a change in attitude towards so-called reactionary films and ideas. The "Soft Film" was one area that scholars were quick to review. One major boost in the second

CINEJ Cinema Journal: Donna ONG 
revisionist wave in the Mainland includes the centennial anniversary of Chinese film celebrated in 2005 that forced scholars and those in the film industry to reflect on the past, as well as the next one hundred years. The influential Dangdai dianying (Contemporary Film) journal for example published a group of articles on the topic of reassessing film history, a number of which were on the "Soft Film". xvi With the centenary, the Beijing Film Archive also made new prints relating to international film festivals on silent cinema which raised the attention of Chinese Silents internationally. Revisionist history continued with the Hong Kong Film Archive's conference entitled "History of early Chinese cinema(s) revisited" in 2009 to celebrate 100 years of HK cinema, as well as the "International Conference: Rethinking Chinese Film Industry: New Methods, New Histories" hosted by the Hong Kong Baptist University in 2010. Most recently two important events hosted in Beijing, 2012: "Rewriting Chinese Film History: A Tribute to Predecessors" to commemorate the 50th anniversary of the History of the Development of Chinese Cinema, shortly followed by the "Pre-1949 Chinese Cinema Conference" indicate the increasing amount of attention on revising this period of film history in the Mainland.

The change in attitude can be seen clearly in the way that history books in the Mainland now no longer condemn the "Soft Film" or the leading "Soft Film" critic Liu Na'ou, and in fact commend Liu for his sophisticated writings on film. Specifically, scholars recognize that the 1930s "Hard film vs. Soft Film" debate is particularly valuable as it was the first major debate on the film industry's aesthetic values and purpose. ${ }^{\text {xii }}$ Several scholars continue to look deeper into Liu and the "Soft Film" with the hope of uncovering previously unknown film cultural heritage. ${ }^{\text {xvii }}$ Some scholars also see a common theme with the 1930 s and today, such as commercial consumerism and the exploration of film form. ${ }^{\text {xix }}$ Understanding the development of the industry and the connection between mass culture and film of the 1930s can also help to find a possible answer to contemporary conflicts between art and commerce, politics and entertainment. ${ }^{\mathrm{xx}}$

Their studies remain small in scope but provide some important findings and alterative approaches that can be further developed, for example the connection between the nature of Neo-sensationalist literature (which was led by Liu Na'ou and Mu Shiying) and the "Soft Film", as well as its leanings towards Western culture and capitalism. As an increasing number of studies are reading deeper into the "Soft Film" critics and their articles, one important issue raised is that although Liu Na'ou's articles did target the Left, and his ideas of film as art were adopted by other active critics in the debate, he himself never engaged in rebuttals as Huang Jiamo and Mu Shiying did. Moreover, findings show a diversity of ideas between the identified critics, which suggests that the term "Soft Film" simplifies and creates misunderstandings about the content of their work. 
Despite this drastic change in attitude, this second revisionist wave in the Mainland and overseas continues to rely heavily on the 1963 text. The "Soft Film" is still dealt with lightly in general historiographies of the period. Aside from shorter Mainland and Taiwan Chinese journal articles that have raised many important issues in revising our understanding of Liu Na'ou and "Soft Film", there have been no complete studies or attempts to problematize the "Soft Film" done to date. It is often described briefly as entertainment films and seen mainly as a counter-movement to the New Culture films. The primary facts and confusions about the term "Soft Film" and Liu Na'ou continue to exist, for example contradictions when defining and categorizing the "Soft Film" e.g. Yihua-made, KMT friendly, entertainment films and hanjian films. Moreover, several Mainland scholars, including prominent scholar Li Daoxin continue to attach political opinions on Liu Na'ou and the "Soft Film" for their affiliations with the Kuomintang and Japanese during the war.

The absence of a complete study of "Soft Film" critics and films reflects the deep legacy that this book has had on the mainstream narrative of the period. The entrenchment of the Leftist canon and terms defined in the official film historiography continue to be found in most Chinese film history books and chronologies today. Although overseas scholars have made crucial contributions to revising history and are less confined by nationalist judgments like their Mainland counterparts, they too have also admitted to relying heavily on The History of the Development of Chinese Cinema ${ }^{\mathrm{xxi}}$ It is also interesting to note that while major breakthroughs have been made on revising the 1920s, Orphan Island, wartime Japanese propaganda films and post-war films, the same has not been achieved with the "Soft Film" movement.

\section{Beyond the archive: new revelations about Liu Na'ou and the "Soft Film"}

An important development in revisionist studies of the "Soft Film" are the efforts to venture beyond the politicized "Hard film vs. Soft Film" debate and recognition that there is much to excavate in archival documents about these previously condemned films and critics. One significant contribution to this has been the publication of the complete works of leading "Soft Film" critic Liu Na'ou in 2001 in his home nation Taiwan. ${ }^{x x i i}$ This has provided a critical opportunity in reevaluating both Liu and the movement as a whole. Improved cross-straits ties has enabled these new discoveries about Liu to also impact Mainland revisionist works. It has revealed new facts and publications that lie beyond the established "archive" which Foucault defines as the set of documents collected or selected that are aligned with master narratives. ${ }^{\text {xiii }}$ Revamping and expanding the old archive has already allowed for new discoveries and corrected basic facts about Liu

CINEJ Cinema Journal: Donna ONG 
Na'ou's life such as his date of birth and death as 1905-1940 as opposed to 19001939 , and dispelled rumors that he was half Japanese. ${ }^{\text {xiv }}$ Further exploration of external sources can be used to challenge the orthodox definition of "Soft Film", and determine the nature and cohesiveness of writings by its associated critics.

The new attitude towards Liu Na'ou in post-martial law Taiwan is similar to the attitude of scholars in the Mainland during the era of opening up and reform in the 1980s. In the forward of Liu Na'ou's Anthology's Film Volume Dianying Quanji, the Tainan County Commissioner Mark Chen writes that accepting Liu now is not only a celebration of his works, but also a celebration of a new liberal attitude to accept multiculturalism and abolish past prejudices. The many forwards in the Liu $\mathrm{Na}$ 'ou anthology written by officials imply Liu's new revered status as a cultural icon. As Liu's hanjian label also made him a taboo topic in Taiwan, Peng Xiaoyan mentions how Liu's family in 1997 (over ten years after the martial law was lifted) still felt apprehensive about whether it was safe or appropriate to hand over the diary entries to her. ${ }^{\mathrm{xxv}}$ It was not until 2001 when Xu Qinzhen compiled the complete anthology of his works that the family and scholars recognized the importance of Liu's work.

In fact, during the 1980s and 90s Liu Na'ou had already played an important part in earlier revisionist studies of literature and Chinese modernity for introducing Neo-sensationalism from Japan to China. He is currently still better known in literary studies as a representative of Haipai (Shanghai style) literature that scholars have used to challenge the May Fourth tradition. Newly recovered materials in his anthology and biography have helped to further these literary studies and also cultural studies of Chinese modernity, such as Peng Hsiao-Yen's study of Liu Na'ou in Dandyism and Transcultural Modernity: The Dandy, the Flaneur, and the Translator in 1930s Shanghai, Tokyo, and Paris that analyses Liu as a cultural translator, dandy/flaneur and propeller of modernity. In the field of film studies, newly rediscovered articles related to Liu Na'ou have been crucial in deepening the understanding of wartime film. Tsuji Hisakazu's Chinese Film history (A soldier's memoirs on Sino-Japanese film) in 1987 and Shizue Tamura's 2010 book Li Xianglan's lover: film and war are detailed accounts of Japanese film propaganda efforts during the war featuring the pivotal role of Liu $\mathrm{Na}$ 'ou as a local agent. Such revelations about the life and works of Liu Na'ou and his affiliates should be emulated in the study of the "Soft Film".

The complete anthology has already paved the way to closer studies on Liu's ideas of film aesthetics, in particular his theories of "Pure Cinema" and "Ecranesque". xxvi His translations and integration of Arnheim's Film Art, European Pure and Absolute cinema movements, Soviet Montage and latest trends in Western Film has already drawn enthusiastic attention from scholars. However one crucial component of his writings that scholars so far have missed is the 
adaptation of Western film theory and trends into the Chinese context of the 1930s. Scholars so far have read Liu Na'ou's aesthetic arguments without considering the social and political background, or trends in the film industry, which results in highly technical and limited readings. As a result, it is equally important to study the world that Liu Na'ou lived in and the people and ideas he worked with in order to fully explicate the meaning and value of his ideas.

We should instead reposition Liu back into his historical context to understand what drives his work. An important fact that scholars have overlooked is that Liu's works were driven by a deep passion for film combined with a strong sense of nationalism - contrary to the long-standing traitor taboo attached to his name. The overriding theme of his writing is a quest to improve what he saw as the embarrassing state of film production in Chinese cinema, in order to boost the image of Chinese people and create a strong national cinema to combat the dominance of Western films in the local market. Liu Na'ou was also fixated with the question of what makes a film successful and a work of art. Through reading cutting edge Western films and theories, he finds his answers to the problems he identifies in Chinese cinema. In particular, he adopts Formalist film theory that emphasizes elements in film production to create style and communicate meaning to promote the idea of Film as an art form. Liu believed that Chinese filmmakers failed to appreciate film as an art form distinct from other mediums and lacked the basic understandings of film production. His many articles on technique as well as introductions of Western ideas and experiments in film that are omitted in the official history, show a clear motive in his writings to raise the status of film as a serious art form and not simply a mass commodity.

The anthology also proves he was not against Socialism in film as the official history claims, but rather against the disregard of film art for crass politics. As his reflections on film show, his fascination with the experience of watching film and its impact on the viewer plays a large part in his theories on film art. This emphasis on psychological impact, which he also borrows from leading Western theorists such as Hugo Münsterberg, is the thrust of his criticism against the Leftists. He argued their films were too forceful in shouting political slogans and did not know how to utilize the elements of film to express it through emotion and experience, which Liu Na'ou believed was much more successful in conveying meaning and winning over the viewer.

Only by understanding the origins of Liu Na'ou's ideas, combined with an understanding of his context, peers, film industry and contemporary audience, is it possible to extract full meaning of his works. Therefore, the newly available resources and growing literature on Liu Na'ou is an effective entryway into exploring and challenging the orthodox notion of "Soft Film". As it is a discursive

CINEJ Cinema Journal: Donna ONG 
formation and not a clearly defined movement, using Liu Na'ou as a guide into uncharted territory will be effective in making linkages between people, ideas and events to construct a larger view of what these affiliated critics and films represented. It is necessary to continue expanding the "archive" to fully explicate whom and what was associated to it. Looking into the Modern Screen Journal, which is said to have served as the base of the "Soft Film" critics, is one example that shows that anti-Lefitsts were not confined only to critics Liu Na'ou, Huang Jiamo, Mu Shiying and Jiang Jianxia as identified by the official history. It also reveals the nationalist drive and commitment to improve Chinese films through introducing Western film trends that shares common themes with Liu's work. Exploring the backgrounds of the critics will likewise help to establish whether they were really Rightists and associated with the Kuomintang as the Leftist narrative claims. This is especially important in understanding the cultural origins of these film critics and their modernist disposition that can contribute to studies of Republican era Shanghai.

To ensure a complete study of the term "Soft Film", it is also essential to examine the films that have been defined in the official and mainstream history that continues today. Findings about their style, content and reception may provide information that challenges or renovates the canon and our current understanding of the 1930s films as largely dominated by Leftists and Left Wing classics. Again using Liu $\mathrm{Na}$ 'ou as a central focus is effective due to the availability of his documentary film Man with a Movie Camera (1933, inspired by Dziga Vertov's film of the same name) and the script for Yongyuan de weixiao (1937). A close study of these will reveal how he applied his film theories onto the screen. A comparison with other existing "Soft Films" will establish whether these films belong to a Genre and are part of a same movement as expressed in film criticism.

A comprehensive study of the "Soft Film" is therefore possible and imperative in revising and filling long recognized gaps in the mainstream film historiography. Providing a new look at the "Soft Film" will be an important addition to the revisionist efforts in achieving a new understanding of 1930s Chinese cinema as a whole. The significance of Liu Na'ou and his affiliated "Soft Film" critics in showing for the first time how classic Western film theories was applied to the Chinese context will greatly contribute to our cultural understanding of the intellectual exchanges between China and the West in Republican era Shanghai. After over seventy years, one hopes that we can objectively study previously condemned critics and clear up the stigma and enigma of those associated with the "Soft Film". 
${ }^{\mathrm{i}}$ According to Gong Sunlu (Zhongguo Dian Ying Shi Hua. Xianggang: Nan tian shu ye gong si, 1962), only three film yearbooks were written in the pre-1949 period. It appears that only the one from 1934 survives today. Furthermore Gong found that just one book on the period by Yang Cun titled Zhongguo Dian Ying Sa Nian (1954) existed prior to 1960.

ii Although the book's co-authors Li Shaobai and Xing Zhuwen are said to have written most of the book, the authorship of the book has been credited mostly to Cheng Jihua whose scholarship was weaker among the three. In this essay, I also use Cheng Jihua's name to represent the authors. According to veteran scholar Li Suyuan, Xing Zhuwen was the main author of the book writing seven of the eight chapters, while Li Shaobai wrote one, suggesting that Cheng Jihua did not contribute to the writing of the book.

See http://shaoyis.wordpress.com/2012/10/01/rewriting-chinese-film-history-symposium/

iii The "918" and " 218 " incidents are two crucial events that marked growing Japanese aggression in Mainland China. The "918" or Mukden incident refers to the Japanese military invasion and occupation of Northeast China (Manchuria) on September 18, 1931. This was shortly followed by a brief war in Shanghai that broke out on January 18, 1932 between the Republic of China and Empire of Japan.

${ }^{\text {iv }}$ Zhang, Zhen July. An Amorous History of the Silver Screen: Shanghai Cinema, 1896-1937. (Chicago, Ill.: University of Chicago Press, 2005) p82

${ }^{v}$ Foucault, Michel. "The Archeology of Knowledge." New York: Harper \& Row, 1972.

${ }^{\text {vi }}$ Prior studies of Chinese film history made little or no mention of Liu Na'ou or the "Soft Film". For example, both were omitted in Hong Kong publications by Yang Cun (Zhongguo Dian Ying Sa Nian. Xianggang: Shi jie chu ban she, 1954) and Gong Sunlu (Zhongguo Dian Ying Shi Hua. Xianggang: Nan tian shu ye gong si, 1962); Liu Na'ou is only mentioned in passing for his work with the KMT film studio by Taiwanese scholar Zhong Lei (50 Nian Lai De Zhongguo Dian Ying. 880-04 Tai chu ban. ed. Taibei shi: Zheng zhong shu ju, 1965) in his KMTcentered narrative. Even in a segment of a book on the general history of film by Hong Ying (Dian Ying Shi Hua. Xianggang : Xue wen shu dian, 1955), the more left leaning account of the Chinese film industry that praises the patriotic efforts and socially conscious films of the 1930s also makes no mention of this theoretical debate or any opposing forces.

vii Cheng, Jihua. Zhongguo Dian Ying Fa Zhan Shi. edited by Shaobai Li and Zuwen Xing. 880-06 Di 1 ban. (Beijing: Zhongguo dian ying chu ban she, 1963). p410-411

viii White, Hayden V.Metahistory: The Historical Imagination in NineteenthCentury Europe. (Baltimore: Johns Hopkins University Press, 1973), p9 
ix Ibid. p14

${ }^{x}$ Ibid. p15

${ }^{x i}$ Foucault, Michel. "The Archeology of Knowledge." New York: Harper \& Row, 1972.

${ }^{x i i}$ Du, Yunzhi. Zhongguo Dian Ying Shi. Taibei: Taiwan shang wu yin shu guan, 1972.

xiii Leyda, Jay. Dianying: An Account of Films and the Film Audience in China. Cambridge, Mass.: MIT Press, 1972.

${ }^{\text {xiv }}$ For example, Ke Ling's article "May fourth movement and Chinese cinema" in An Interdisciplinary journal of Chinese film studies (Xianggang : Xianggang Zhongguo dian ying xue hui, 1983). Information about the rehabilitation of 1930s Leftist films is mentioned in Zhang Zhen's book An Amorous History of the Silver screen: Shanghai Cinema, 1896-1937 (2007)

${ }^{x v}$ As conveyed to me by Dr. Esther Yau in 2012 based on her reading of the journal Dangdai dianying and discussion with Li Suyuan.

${ }^{x v i}$ see Meng Jun. "The Apocalypse of the Controversy between the Hard Films and the Soft Films." Dangdai Dianying.002 (2005): 79-82. and Li Suyuan "Liu Naou's Film Ideas: the Aesthetic from the Modem Perspective." Dangdai Dianying.02 (2006): 62-65.

xvii An Yan. "Rereading Soft Film Theory." Dianying Yishu.05 (2003): 113-15; Huang Xianren, "Reexamining the 1930s Soft Film Debates." Dianying Yishu.03 (2002): 91-95+90. Print.

xviii For examples, see Li Jin, "Neo-sensationalism and 20s, 30s Hollywood film." Zhong Guo Xian Dai Wen Xue Yan Jiu Cong Kan 3 (1997); Chen Xihe, " Construction of the modern film theory - re-evaluation of "Neo-sensationalism's" film theory legacy." Journal of Shanghai University (Social Science Edition).02 (2011): 16-22. and Xue feng "The Establishment of Visual Aesthetic Criticism and Modern Chinese Film Art Criticism." Dangdai Dianying.06 (2011): 96-103.

xix Shi Hui, "A look at 1930s Soft Film." Nanjing Shehui Kexue.02 (1999): 54-59.

xx Pan Jian, "Movies as Entertainment: On Huang Jiamo's Film Approach." Journal of Beijing Film Academy.002 (2005): 33-38.

${ }^{x x i}$ Influential overseas studies of the period include works by Poshek Fu, Leo Lee Ou-fan, Pang Laikwan, Paul Pickowicz, Emilie Yeh Yueh-yu, Zhang Yingjing and Zhang Zhen.

${ }_{\text {xxii }}$ Liu Na'ou Quan Ji. edited by Na'ou Liu, Laixin Kang and Qinzhen Xu. Tainan Xian Xinying Shi: Tainan xian wen hua ju, 2001.

xxiii Foucault, Michel. "The Archeology of Knowledge." (New York: Harper \& Row, 1972), p128-129.

xxiv See Xu Qinzhen's biography of Liu Na'ou Mo Deng, Shanghai, Xin Gan Jue : Liu Na'ou (1905-1940). 880-04 2 ban. ed. Taibei Shi: Xiu wei zi xun ke ji gu fen you xian gong si, 2008. 
${ }^{\mathrm{xxv}}$ Peng, Hsiao-yen. Dandyism and Transcultural Modernity: The Dandy, the Flaneur, and the Translator in 1930s Shanghai, Tokyo, and Paris. (New York, NY: Routledge, 2010), p56; "Colonialism and the Predicament of Identity: Liu Na'ou and Yang Kui as Men of the World." In Taiwan under Japanese Colonial Rule, 1895-1945: History, Culture, Memory, edited by Binghui Liao and Dewei Wang. (New York: Columbia University Press, 2006), p239

${ }^{x x v i}$ The international conferences on Liu Na'ou held in 2005 and 2011 have included several studies exploring his ideas of film and influences such as What is a "pure film"?: A discussion on Liu Na'ou theory system (Pavel Byzov), Research Note: Range of Liu Na'ou's Film theory (Mami Misawa), From "Poetic image" to "Soft Film": Liu Na'ou's "image - constitutive sentence" aesthetics and its fate (Xu Minghan) 